\title{
A Professional Teacher Work Agenda Teaching in Higher Education
}

\section{Rosiane Rocha Oliveira Santos, Josenilton Nunes Vieira, Marcelo Silva Souza Ribeiro, Claudia Maria Lourenço da Silva, Vania Cristina Lasalvia, Antônio de Santana Padilha Neto}

Faculdade de Ciências Aplicadas e Sociais de Petrolina,Petrolina, Brazil

Email: rosi.rocha@facape.br, josenilton.vieira@facape.br, marcelo.ribeiro@univasf.edu.br, claudia.lourenco@facape.br, vania.lasalvia@facape.br, padilha.neto@facape.br

How to cite this paper: Santos, R. R. O., Vieira, J. N. Ribeiro, M. S. S., da Silva, C. M. L., Lasalvia, V. C., \&de Santana Padilha Neto,A.(2019).A Professional Teacher Work Agenda Teaching in Higher Education. Creative Education, 10,1383-1399. https://doi.org/10.4236/ce.2019.107103

Received:May31, 2019

Accepted: July7, 2019

Published: July10, 2019

Copyright $\odot 2019$ by author(s) and ScientificResearch Publishing Inc. This work is licensed under the CreativeCommons Attribution International

License (CC BY 4.0).

http://creativecommons.org/licenses/by/4.0/

\begin{abstract}
This research investigated the challenges of teaching in a professionalinstitution of higher education in the state of Pernambuco, located in the São Francisco Valley Development Territory. questioned the events of continuing education and the impact of these on the professional development of teachers, with an emphasis on size constitutive teaching of teaching identities. Established the following objectives: to examine the alternatives accepted by teachers as investments in professional development as a teacher; check the impacts of training experiences in the professional development of teachers; analyze the role of pedagogical mediation processes in the construction of teachers' identities. The theoretical research in March is defined based on the concepts of profession and professionalization, highlighting trends based on historical dialectic materialism, which gives theoretical support to the historical-critical pedagogical trend. The methodology was characterized by qualitative approach, triangulating techniques to obtain information such as questionnaires, individual and group interviews, as well as participant observation. The systematization and analysis of the results highlight that less than $70 \%$ of survey participants teachers have made some kind of investment in their pedagogical training. The training events with the greatest impact on professionalism are those related to the search process. We conclude that one of the challenges of professionalization in the institution studied is the need to implement a continuing training policy which has principle research and critical reflection on the educational processes experienced in higher education. This involves the expansion and strengthening of the role of pedagogical support, seen as an essential vector in the coordination of events related to the teacher education research institution, since most of their teachers did not attend disciplines of teaching and pedagogical basis of their initial training, a fundamental element in the constitution of teacher identities.
\end{abstract}




\section{Keywords}

Teacher Professionalization, Pedagogical Training, College Education

\section{Introduction}

The expansion of higher education scenario experienced in Brazil in the first decades of the twenty-first century is the expansion of educational opportunities for a significant number of young Brazilians who hitherto only dreamed of the possibility of joining a course that level. This phenomenon sets up a cultural development opportunity, social, political, economic and technological in multiple dimensions.

In the individual aspect, access, remain and complete a degree leverages significant changes in people's lives. These are manifested in the professional field, epistemic and citizenship in societal relations(Severino, 2007). It is a phenomenon that occurs with the acquisition of specific skills, expansion of cultural repertoire, development of communication processes, incorporating new features to the codes of language, use of new technologies in the productive dynamics and social interaction.

From the point of view of the community, the expansion of educational opportunities at the top level involves increasing the population's education index, which creates the expectation of significant impact on the quality of social life, since schooling is adopted by multilateral agencies development as one of the reference indicators of quality of life in society.

Beyond what is stated above, the expansion of higher education also is the possibility of epistemological gains in an inverse logic and/or descolonizante since opening its doors to new population groups, universities and other institutions of higher education They start to live daily with new modes of production of material existence and symbolic. These logics enter this educational space with people belonging to classes previously excluded from higher education.

In the São Francisco Valley, specifically, at the meeting point of the northeastern states, Bahia and Pernambuco in the cities of Juazeiro and Petrolina, higher education has made important contributions to the multidimensional development of this micro-region, despite the unequal distribution of income among social classes limit the opportunities for people disadvantaged economically.

Among the higher education institutions, existing in this micro-region, the surveyed college is configured as one of the oldest in this context. This results from the process of internalization of higher education in Pernambuco, in the 1970s, which has as one of its brands, the creation of state and municipal authorities.

Considering the importance of the aforementioned college, in this context of significant changes in the production processes of material and symbolic goods, this research sought to know: What are the areas of continuing education, at- 
tended by teachers of this institution and what are the impacts of these formative dynamics in the development professional, while teaching the professionalization process in higher education?

In their research objectives set out to examine the implications of teacher training in the process professionalization of teachers surveyed; identify training environments frequented by teachers in the last eighteen (18) months; analyze the impacts of training experienced in the professional development of teachers; demonstrate the limits and prospects in the construction of teachers' identities in the context of the research institution.

The relevance of this study is through a different view of the pedagogical action in higher education, in addition, guided discussions about the multiple identities that are constructed/deconstruct/reconstruct in educational environments, requires contemplate and analyze which elements contribute directly and indirectly to the phenomenon of reconstruction of identities, especially with regard to the exercise of teaching practice in bachelor's degree programs.

In this sense, the look of the research was aimed to know how the educational activities may contribute to this phenomenon, on-site survey cited, considering that the teaching of the local authority framework consists predominantly bachelors professionals and who have not had as base their training the didactic and pedagogical disciplines.

\section{A Professional Teacher in Higher Education}

A reflection on the professionalism makes us immerse in a field of complex relationships and multiple meanings and meanings, from which emerge the rules, conflicts, contradictions, the consensus, the statutes, laws, models, organizational principles, methods, techniques, theories, practices, knowledge, knowledge, status, recognition and professional valuation.

Based on the ideas ofBerger and Lukman (2004) that reality is a social construct, it is understood the teacher professionalization as a process of professional development socially constructed in different environments, characterized by its contradictions, conflicts and complexities, changes and transformations historical. In this sense, Nóvoa (1991: p. 21)states that "professional affirmation of teachers is a journey full of struggles and conflicts, hesitations and setbacks".

The contemporary movement to teacher professionalization sets the teacher as reflective and critical social actor researcher. It is a movement whose epistemic bases are founded on currents of thought which, taking into account differences between the different trends, understand the reality as moving phenomenon (Ramalho,Nuñez,\& Gauthier, 2003). It is in permanent motion of a becoming, which develops professional as building teacher identities process.

It is noteworthy that the identity process occurs in a complex way, involving numerous variables. Undoubtedly, one of the most important is the so-called "look the other"(Ribeiro, 2007). This "look the other" seems to have a strong influence on the formation of identity. Certainly there is just this and to under- 
stand the identity process it is necessary to have a dynamic and multifaceted approach.

Without discouraging or devalue the individual aspects of identity singling, but on the contrary, taking into account the social dimension tends to be, especially when it addressed the issue of institutional identity, something prevalent to its constitution.

Continuing to discuss the relevance of "looking the other" as the identity constitutor, mainly from institutional identity, some studies present discussions addressing the organizational culture as macro and which is influenced by the way the institutions are seen, perceived, signified and appropriate.

Several authors(Bowditch \&Buono, 1992;Robbins, 1998;Zanelli, Borges-Andrade, \& Bastos, 2004;Spector, 2005; Vergara, 2005;Santos \& Freitas, 2017) approach, even indirectly, the elements of corporate identity as being part of the organizational culture. The issue of institutional identity, either in its most intentional aspects, caused by management actions, or even the way is appropriate and reworked by the people, has proven relevant in studies that focus on the issue of institutional development.

The corporate identity is therefore understood as dynamic and multifactorial. In terms of dimensions for the identity Van Riel (2003 citedAlmeida, 2005) is perceived understood from the identity of the projected identity of the desired identity and applied identity. All these dimensions would be in interaction and influence the institution itself.

The studyCeretta and Canterle (2011), which analyzes the institutional identity of a public organization of higher education, shows that corporate identity is appropriated and reinvented by the community, affecting even the very development of the institution.

According to Pimenta (2012), discussion on identities teachers emerges in the context of reflections on teacher training and practice in the educational context. These identities, according toAzzi (2012) consist of pedagogical knowledge built into the daily lives of their work, enabling the teacher to interact contextually in the educational environment in which it operates, expressing it in their practice with and from it.

Thus, the identities come to life and materialize through the discourses and practices of certain groups. In addition, identities are plural and compete with each other while the identity of "principal" and identities "supporting" even when the deviser enrolls all and sets in one(Ferreira, 2011;Hall, 1997;Silva, 2000). It is in the context of these plural identities Ferreira (2011)will defend "[...] that there are identities that are always there, pre-existing the supposedly" identical "as immortal souls waiting to take the" body time "in an eternal return process, once set are materialized ad aeternum"(Ferreira, 2011: p. 106).

To think this process in higher education, scholars likeZabalza (2004),Veiga and Viana (2010),Soares and Cunha (2010) have emphasized the uniqueness of this level of education in contemporary life and alerted to the need for professional development of teachers that meet the demands of a society that shows 
increasingly complex. Thus recognizes the need to overcome the reproductive character of the transmission of content, to make way for a teaching practice based on constructionist learning principles from the intellectual autonomy stimulus teachers and students.

The proposition of a new professional teacher profile means a break with the current model of technical teacher. According toContreras (2002), the idea of a teacher as a coach is based on principles such as social division of labor, the functions hierarchy, bureaucratic control, dependence who performs in relation to those planning the pedagogical action, instrumentation, stiffness processes and emphasis on evaluation. In this conception, "the teacher, as a technical professional, understands that his action is the application of technical decisions" (Contreras, 2002: p. 96).

Studies by Tardif, Lessard and Gauthier (2002),Popkewitz (1997)show that the ideal of a professional teacher, reflective, critical researcher and intellectual, are placed on the agenda in the United States in the 1980s as an alternative to the model teacher designed the parameters of instrumental technical rationality. The ideal protection for movement of a teacher who is more than a technical, soon gained adherents in other countries and became part of the prescription in training policies in different contexts.

ForContreras (2002), the reflective teacher bases his pedagogical actions in reflecting on their past experiences, using them as a reference in the everyday practices of this, as well as for planning future actions. The design of the research professor establishes a break with the principles of certainty, linearity and generalization of the findings. In this case, the intentionality of the teacher research turns to the singularities of the contexts which develop educational activities. Therefore, the teaching activity should be guided by the investigative attitude of his practice guided by the critical sense and the willingness to systematize it(Vieira, 2009).

Professional development is stated as a historical imperative in the context of complexities that require critical attitudes of teachers and reflective political positions in society. It is the configuration of these elements in the day-to-day professional practice, the teacher will define their own professional identity. Therefore, the professionalization process is a challenge to be faced by teachers in the context of its activities as well as in the political struggles set in broader dimensions in order to obtain social recognition. In this sense, the initial and continuing training in a multidimensional perspective is an element of the professional development process, which neither teachers nor the institutions that employ them must give up or relegate it to the background.

Currently, there is a consensus that the practice and experience are interdependent and interactive, part of the same process that renews the educational space and the concrete actions. Each stage of professional development is an opening in new times of training and is, in some respects, a renewal and innovation in personal and professional reality, transforming reflective practice in mediating practice of knowledge production that is based on and inspired by the 
experience teacher life. Thus the teacher is constructed from an interactive dialogue and practice between the individual and collective (Gohier, Anadón, Bouchard, Charbonneau, \& Chevrier, 2002).

Admittedly, the practice has a utilitarian dimension when trying to solve only immediate needs, but also has an ideological dimension. The prospect of Libâneo (1995)reinforces this view when he states that "behind the school practice, there are socio-political factors that define different conceptions of man and society and thus communicate different assumptions about the role of school, learning, teacher-relations student, teaching techniques, etc."(Libâneo, 1995: p.19).

Moreover, according toZapata (2004), the practice is not just a simple application of theoretical knowledge, but the indispensable condition for the emergence of any theory. This statement leads us to believe that educational practice can be considered as a source of knowledge development.

Following the work in the field of situated cognition, developed byLave and Wenger (1991), educational practice can be defined as a set of practice and, above all, a practice that needs to be analyzed in context. Moreover, according to Schön (2002), any practice should be reflective: the teacher reflects before, during and after the concrete action. This reflection aims to regulate the action, in order to face the unexpected and analyze their own action to systematize it, understand it or transform it.

Altet (1994) suggests that educational practice is multidimensional as it involves pedagogical, psychological and social dimensions to the educational work both in the classroom management as the process of teaching and learning. Altet (1994)also uses the term educational situation to emphasize the importance of the organizational context.

The didactic and pedagogical dimensions refer to the teacher and student interaction, to planning, to trade in class, the educational proposals and taught content. It is the teacher's skills and knowledge that are mobilized at the time of planning, but also to respond to situations that arise in the classroom.

The psychological dimension refers to social interactions, the exchanges between the teacher and the student and between the students themselves, while the social dimension puts the practice in a social context and particular history, characterized by standards and shared values.

If we consider the observations ofBeillerot (1996), the professional practice refers to processes to be made, ie, both the rule of action as its implementation by an Actor in a professional context, we believe it is both a matter of analysis the chain of actions and exploitation of knowledge, skills and knowledge mobilized or purposes, and institutional and personal bets.

In this sense, many authors define the educational practice according to two dimensions: on the one hand, gestures, behaviors and on the other, the objectives, strategies and implicit rules that guide the action(Barbier, 1996;Beillerot, 1996). So we can say that educational practice is not only one way to do, but also a way of seeing the world. You can not limit the relationship of teacher and stu- 
dent, it is necessary to take into account also the teacher's relations with the institution, colleagues and society in general. AsPerrenoud (2001) argues, the practice is a relationship between the subject and his situation and also a reciprocal relationship involving institutional identity.

It is in the midst of this reflection that it is necessary to reflect "on the type of individual that the university wishes to form a mere technician player of the knowledge acquired in the gym or a citizen endowed with humanistic and capable vision to understand the rapid and sharp social change"(Sanches \&Soares, 2014: p 59)Therefore, the professional who intends to contribute directly towards a critical, reflective and construction of citizen awareness and epistemic practice seeks to add to their training pedagogical foundations of historical-critical pedagogy.

Note that this search is done by means of reflections made from the design of a pedagogy that is counter-hegemonic, questioning, transforming (Saviani, 2003) of existing social relations and fighting order "social transformation through socialization systematized knowledge, i.e. the appropriation of knowledge historically produced by mankind"(Moreira, 2014: p. 13). The steps of this pedagogical current are presented byGasparin (2009) and take place in the respective order: 1) initial social practice content; 2) questioning, 3) instrumentation; 4) catharsis and 5) social practice end of the content.

In this sense, the philosophical basis of historical-critical pedagogy is the transformation of relations of production with a view to a new order conducive to building equity and social justice(Saviani, 2003;Mello, 2007; Gasparin, 2009). It is with this bias that is thought to reflect on the identities teachers and their educational practices, so that these can not be dissociated from social practice.

It is in the context of a local authority that offer only bachelor courses with teachers mostly graduates who enter the educational activities as a possibility interventional, mediator and promoter of reconstruction of teachers' identities, basing the need for these teachers exercise reflections on the process of teaching and learning at the expense of an uncritical attitude,based on an education without reflection(Freire, 2014), according to which the teacher has placed in their students the knowledge you have and the same way as acquired(Demo, 2006; Sanches \& Soares, 2014).

\section{Itinerary Methodology}

This research defines how your approach as a qualitative research by considering, in the process of production and analysis of data, the existential dynamics of social actors contributors to this study, establishing inseparable links between objectivity and subjectivity of people who participate in the processes instituting investigated on organizational culture environment. It is an approach that "arises, with different approaches, as alternatives to research in education" (Triviños, 1987: p. 118). Thus to the qualitative research option implies the orientation of the epistemic-methodological choice and thus the data analysis proposal.

With regard to the method of approach, adopted the references of dialectical 
historical materialism, since the challenges of the professional development of teachers are observed and analyzed as part of a historic and complex whole, which brings with it the components of their own denial, living in constant change, and is interpenetrated by contrary and conflicting elements that contribute to the processes of change that occurs in the teaching reality in the context of the investigated institution.

\subsection{Survey Information}

In the process of gathering of information in the execution of this research we used techniques such as questionnaires, group interviews and participant observation at different times of the study.

The questionnaire was offered to teachers through a form drawn up in google forms platform with a linear range of a 1 to 5 , in which it requested that the teachers demonstrate the degree of importance that each of the reasons mentioned had in the decision to become and remain teachers. The list of options consisted of the following terms: calling, social status of the profession, social commitment, lack of career choice, possibility of extra remuneration, influence others, represent a stable job.

To realize the involvement of teachers with continuing education in relation to the educational dimension in the last 18 months leading up to the questionnaires, we asked the teachers: you took part in the educational workshops promoted by this institution, courses/workshops (for example, on subjects or methods and/or other topics related to education)? You participated in conferences and education seminars (when teachers and/or researchers present results of their research and discuss educational problems)? Did you participate in a training program (for example, an undergraduate level course or graduate school that offers a diploma or certificate)? Did you participate in observation visits to other IES? Did you participate in a network of teachers (network) formed specifically for the professional development of teachers? Did you develop individually or in collaboration on a topic of professional interest research? You had the guidance and/or observation made by a colleague and supervision, formally organized by IES?

The questionnaires occurred with the sending via e-mail and whatso messages to all teachers of the institution, and participant inclusion criteria the fact that statutory teacher or hired by the institution. Exclusion criteria only the refusal to answer the questionnaire. In the universe of 134 (one hundred fifty) teachers, 49 (forty nine) answered the proposed questionnaire.

Another technique used to collect information in the field of research consisted in collective interviews conducted in smaller groups, both in the meetings of the group responsible for research, such as during the meetings of the boards of Accounting courses, Management, Law and Social Service. We chose these because they are the ones who have added the largest number of teachers. At meetings of these boards was given a space to communicate the results obtained 
with the questionnaires. Therefore, the moments of communication of the first search results are configured moments to deepen reflection on the themes of research from the voices of the participants.

As participant observation, this occurred in the daily routine of the pedagogical, allowing a survey of information exactly in the place where the events investigated in the research occur, ie in direct contact with the teachers thus producing a relevant collection of information to deepen the investigation. This became possible due to the privileged status of the researchers who assume a position of participating observers involved in the very object of study. This fact makes these live the day-to-day operations and reflect on the daily life of critical and systematic manner institution.

As a recording instrument of information we used the diary, in this case, provided an analysis and interpretation of situations observed to unravel the networks of experienced meanings of facts in the daily educational sector in interaction with the local authority teachers. The following discussion presented thus reveals the information collected in the field and analytical tessitura about these these, seeking to provoke reflections, readings and lead to new knowledge in the pedagogy field in higher education,in the context of a local authority, With the founding category professional development as part of the construction process teachers identities.

\subsection{The Content Analysis of the Responses}

The analysis considered the index of responses to confirmation criteria or not the formative moments proposed in the questionnaire, as well as the criteria offered for evaluation of impact, the professional development of teachers. In the qualitative dimension analyzed the content of collective interviews recorded on audio and video devices, as well as records produced in the field diary on participant observation of situations. The information was gathered and discussed by the group of researchers and of them compose this text as systematic reflections on what happens in daily teaching practices experienced in the research institution. Therefore, the results discussed in the limits of this article relate to data and information obtained through the questionnaire, and also,of other stages in the research process where the opinions expressed by the teachers are confronted when presenting these results during the meetings of the collegiate students of the courses of the institution promoted by the pedagogical sector of the institution in question.

\section{Results}

Whereas the conditions for professional development involves a set of broader relations, for example, how the teacher perceives in the profession, personal and institutional investments in their pedagogical training, and the stimuli shared within the coexistence with peers, with the institutions that employ and other fields of social life, from which emerge the rules, regulations, codes of conduct, 
first, recognition, appreciation, everything that makes up the essence of the teaching. Within the limits of this text highlight only the results for the reasons that contributed to the entry and stay of teachers in the teaching profession, as well as teacher training events which took part in everyday invention of this profession.

Search results expressed in the responses to the questionnaires as well as in times of discussion in educational workshops in the weeks of planning promoted by the institutionshow that the most significant reasons for the entry of teachers in the teaching career were the vocation and social commitment. Elected categories as having medium importance, according to the responses were social status of the profession and the representation of stability. Already the lack of other professional option, the possibility of an extra pay and the influence of other/the person/were the categories defined as of little or no importance to the choice of the teaching career.

In the aspect of the formation rate of participation in some kind of continuous training event in the last eighteen (18) months ranged below 70\%, with an average of participation in the various events estimated at $49.21 \%$. It stands out as events that had the greatest participation seminars and meetings in which they discussed the search results with 68.3\%; pedagogical days with $66.8 \%$; development of individual or group research in the last 18 months on their professional interest, $66.7 \%$.

A closer range of the average participation in training events mentioned in the questionnaire was checked with teachers who participated in professional training courses offering certificates and diplomas, $46.3 \%$ answered yes in which other was the participation in observation visits the other IES $45.2 \%$. The options that recorded the lowest rates of participation of teachers was the participation network of teachers (network) formed specifically for the professional development of teachers in the last 18 (eighteen) months, only $31.7 \%$ of the respondents said they participated. On the direction and/or observation made by a colleague and supervision, formally organized by IES. Only $19.5 \%$ had this kind of experience in the last two years.

Regarding the impact of participation in the aforementioned events, we tried to see which of them had great impact or moderate impact on the professional development of teachers.

Regarding the impact of these training events it was found that among those who had greater involvement of teachers, which produced more relevant impacts were those related to the research, in this case the seminars and meeting in which they discussed research results It had great impact for $27.6 \%$ of the participants, or moderate impact to $48.3 \%$, which it follows that the event was significant with good acceptance for $75.9 \%$ of the participants.For the development of individual or group research in the last 18 months on their professional interest to $42.8 \%$ produced a great impact, to $46.4 \%$ produced a moderate impact, which means that $89.2 \%$ of participants recognize research as a relevant event in their professional development. 
Sought to further understand the impact of educational seminars held every beginning of semester, it was observed that this type of event had a major impact only to $10.3 \%$ and moderate to $48.3 \%$. What allows us to say that this kind of event has some relevance to $58.6 \%$ of the teachers who participated in educational workshops.

Regarding the impacts of programs or professional training courses offering certificates and diplomas, $70 \%$ believe that this type of event produced a great impact on their professional development as a teacher. To $15 \%$ produced a moderate impact therefore reveals an acceptance of $85 \%$ as a significant experience. Regarding the participation in visits to other higher education institutions to $33.3 \%$ of these experiments produced a great impact on their professional development, while $42.8 \%$ consider that produced a moderate impact, this means a trend to recovery and healthy event kind of recognition for the training and professional development of teachers.

The participation in a network of teachers (network) formed specifically for the professional development of teachers, 38.5\% for those activities had a major impact on professional development, to $30.7 \%$ was a moderate impact,

As for guidance and/or observation made by a colleague and supervision, formally organized by IES. Among these, $62.5 \%$ consider that this experience had a major impact, 37.5 the experience of being guided by a colleague had a moderate impact, so this seems to be one of the most beneficial experiences for teachers who had the opportunity to experience it.

\section{Discussion}

Responses to the questionnaire could be a tacit indication of confirmation that the words listed by teachers in teaching week workshop reveal, in fact, their perceptions of their teachers' identities and how this is revealed in their daily academic, as the practical driver, not the choice of being a teacher, social commitment category would be associated with political words, responsibility and sensitivity, learning, educator, commitment, provoke, arouse.

It is from this angle that we think the construction of teachers' identities as a process and not a product. In the case of local authority of staff concerned, the identities are mainly associated with the vocation and social commitment that each teacher identifies profile to pursue the career. Thus it is necessary to realize the important role that has the pedagogical support of the institution so that it will act to bring about the recognition of these identities, as well as its constant reconstruction.

Why, then, the pedagogy of intervention as a mediator of construction of these identities? Because the understanding of what is a vocation or social engagement is very important so that teachers can act in the face of a society that undergoes a transformation and is that where they are based professors and students. To understand their work as a vocation, the teacher can move away from the practice that should be guiding chief of their work, which is the social com- 
mitment, in this case the resources, methodology, addressed pedagogical trend or even your relationship with the student may be imbued with a vision backed by something which of course does not exist according toBourdieu $(1999,2007)$. Therefore, the intervention of the pedagogical advice should act to mediate such understandings,

For him, the vocation is not present in genetics, but is the result of culture, in their capacity as structuring structure of social relations, according to which "the effective vocation includes, as a provision acquired within certain social circumstances, the reference to its conditions (social) of embodiment which tends to adjust the objective potential"(Bourdieu, 1999: p. 89).

The impact of the experiences of the teachers provides indications that it is important to invest in promoting the institution of seminars that allow the discussion of research in the teaching field. This can happen both from the point of view of the discussion on conducting research by teachers, how to open dialogue with researchers from other universities on educational issues in this regard, also fits the stimulating research, as well as the encouragement of their teachers maintain exchanges with other higher education institutions (HEI) to address this issue.

As for pedagogical days is indicative that although this type of event is considered important for $58.6 \%$, it is necessary to review both the content and the methodology of events to promote continuing education. So that produce a significant impact on the professional development of teachers. This involves the production of diagnoses of the actual training needs of teachers, as well as promote training times more often than can develop naturally in the inventive daily lives of teachers.

It is also suggested investing in the development of longer courses, with some theoretical density and practice in order and make more meaningful the continuous teacher training policies, another aspect to consider is the stimulus for teachers to engage in this type of training by developing lines of research and studies in order to discuss the issue of pedagogical training of teachers.

This result suggests stating that the institution should invest in the network of training partnerships with regional, national and international institutions to establish exchanges and to promote visits from their teachers to other institutions, as well as receive professors from other institutions who can share their experiences in educational field, either through visits, whether through courses, organization of seminars, meetings, symposia to exchange innovative experiences in teaching in the areas of operation of the institution.

To take advantage of the formative power of collective action is important that the institution develops strategies to overcome the individualized research practices. For this, you can stimulate the formation of research groups involving teachers and students, ensuring institutional conditions for the development of collective research practices.

The survey results indicate that one way to strengthen the educational dimen- 
sion in the teaching professional process in the research institution, goes through pedagogical mediation that should be articulated by educational advice. In the case of the institution concerned, the local authority has the work of two pedagogues who work daily in the municipality, developing among other things, monitoring of academic activities with regard to teaching and student care as well as in the construction and review of institutional projects and in partnership with the academic board.

The latter has indeed understood this need, corroborating the claim that Sanches and Soares (2014: p. 78)point out that when:

Many of the leaders of higher institutions already understand the need to encourage the training of its professionals, both in the sense of acquiring new skills as teacher improvement of its faculty. This is due to the constant need to innovate and expand the didactic and pedagogical knowledge.

From the observations and the local authority case study, you can easily understand that the statement of the authors is consistent with the practice of the last three administrations of the academic board of the institution, despite having diverse initial training-Philosophy, Management and Engineering, have acted positively that encouraging training and expansion of didactic and pedagogical knowledge faculty. So much so that the bringing of training events aimed at improving the quality of teaching emerges from the inquiries of their own academic board.

Importantly, such an interest on the part of managers can is associated with own continuing education experienced by teachers who have taken the academic director function of the institution, considering that all had the experience of attending a post-graduate studies program. Corroborating this idea, Demo (2007)asserts that this is due to the fact that to go through a post-graduate studies program, many of the teachers tend to have another practice and have a look at each other.

Importantly, however, this is not the case of all teachers trained in the strict sense level, not only within the institution, but overall.

We can not force such data because in addition to refer to a single point in time, can not guarantee that graduate is infallible remedy. Titles do not guarantee competence. What guarantees the appropriate learning? You can also learn pedagogical weeks, depending upon the teacher who does. After all, there are students who learn well despite the teacher(Demo, 2007: p. 4).

Hence we corroborate with Demo by stating that the teacher Brazil need to study, because for every context presented here, we see that there are numerous challenges to reach a critical practice, reflective, contextualized and emancipatory, supported in Demo perspective(Demo, 2007) which proposes to be a practice of systematic studies developing a dense critique of the educational environment. Certainly, we corroborate stillSeverino (2007: p. 73) when he says that the teacher identities spend the signification of "a social practice of 
broader intervention, reaching other areas of life and society" (Zeichner, 2003).

It is in this constitutive process of identities teachers that the teacher works with your student not only a localist perspective of the classroom, but it contributes to social change, thought the mediation developed in the municipality, however, this work requires effort pedagogical support to promote reflective moments on the identities teachers and a continuous and consistent monitoring.

Therefore, teachers reconstruct and reflect on their identities based on the concept that work with a social commitment, which is the bias approached by the historical-critical pedagogy, can act much more politicized way, awareness-raising and, especially, transformative. Not the teacher who realizes his vocation as the main guiding his career is incapable of it, but the relevance that will realize its social commitment as practice guidance is that it will lead to an understanding of a job, even though it is not possible only the teaching practice to solve social problems, "it may be that they can not change certain aspects of the present situation, but at least will be aware of what is happening"(Zeichner, 2003: p. 47).

\section{Final Considerations}

Overall, the results of this research bring subsidies for the understanding of the unfolding of the training policy implemented by the research institution, to highlight the reasons that influenced the attitude of people collaborating in this research constitute teaching professional. It was evident that most teachers associates choose the teaching career to social commitment and vocation. However, there is a further need to discuss these two categories both reflective of the research group and the work to be developed by the educational sector of the municipality, in order to build a reflection on the vocation of perspective may be associated with deterministic factors naturalized in society by structural issues.

The results suggest that the faculty of this institution is little encouraged to seek a pedagogical training as an investment in their professionalization. Therefore, one of the institutional challenges of the institution is to develop a policy of incentives to teachers in order to incorporate the pedagogical dimension as desired item and sought in their professional development as a teacher.

Regarding the impacts on professional development for their participation in various training events it is clear that the institution needs to produce diagnostics that enable you to plan and execute a continuing education policy for teachers based on training needs.

\section{Conflicts of Interest}

The authors declare no conflicts of interest regarding the publication of this paper. 


\section{References}

Almeida, A. L. C.(2005). The Influence of Identity Designed in Organizational Reputation. Ph.D. Thesis, Belo Horizonte: Federal University of Minas Gerais.

Altet, M. (1994). Une démarche de recherche sur la pratique enseignante: L'analyze plurielle. Pédagogie Revue française, No. 138, 85-93. https://doi.org/10.3406/rfp.2002.2866

Azzi, S. (2012). Teaching Work: Teaching Autonomy and Construction of Pedagogical Knowledge. InS. G. Pepper(Ed.),Pedagogical Knowledge and Teaching Activity (8th ed.). São Paulo: Cortez.

Barbier, J. M. (1996).Savoirs théoriques savoirs et d'action. Paris: Presses Universitaire de France.

Beillerot, J. (1996). La Formation Formers. Buenos Aires: Ediciones Novedades Education.

Berger, P. L., \& Luckmann, T. (2004). The Social Construction of Reality: Treaty of Sociology of Knowledge. Rio de Janeiro: Editora Vozes.

Bourdieu, P. (1999). Class Future and Causality of the Probable. In M. A. Walnut,\& A. Catani(Eds.), Pierre Bourdieu: Written Education(2nd ed.). Petropolis: Voices.

Bourdieu, P. (2007). Cultural Reproduction and Social Reproduction. In The Economy of Symbolic Exchanges. Sao Paulo: Perspective.

Bowditch, J. L.,\& Buono, A. (1992). Components of Organizational Behavior. São Paulo: Pioneering.

Ceretta, G. F.,\& Canterle, N. M. G.(2011). Analysis of Organizational Identity: The Case of a Public Institution of Higher Education in Southwest Paraná. International Congress of Administration, 1.

Contreras, J. (2002).Autonomy Teachers. São Paulo: Cortez.

Demo, P. (2006). Yet the Questions: What Is Pedagogy, Who Is the Teacher, What Should Be the Faculty of Education? In S. G. Pepper (Ed.), Education and Educators: Paths and Perspectives (2nd ed.). São Paulo: Cortez.

Demo, P. (2007). Is Necessary to Study. In A. M. Britto (Ed.),Forming Memories: Records and Tracks in Different Contexts. Campo Grande: Editora UFMS.

Ferreira, M. O. V. (2011). Construction Identities Teachers: between Vocation, the Objective Needs and Social Processes. Educação, 34, 106-113.

http://webcache.googleusercontent.com/search?q=cache:kWg7IxzrMOQJ:revistaseletro ni-

cas.pucrs.br/ojs/index.php/faced/article/download/8672/6133+\&cd=1\&hl=pt-BR\&ct=cl nk\&gl=br

Freire, P. (2014).Pedagogia do Oprimido (58th ed.). São Paulo: Paz e Terra.

Gasparin, J. (2009).A Teaching for Teaching Historical Critical (5thed.). Campinas, São Paulo: Authors Associates.

Gohier, C., Anadón, M., Bouchard, Y., Charbonneau, B.,\&Chevrier, J.(2002). de l'identité professionnelle enseignant quand l'il se fait formateur Maîtres: continuité or rupture? In D. Baillauquès, S. M. Lavoie, M.-L. Chaix, \&J. C. Hétu (Ed.). L'identité chez les formateurs d'Enseignants. Échanges franco-québécois(pp. 195-215). Paris: L'Harmattan.

Hall, S. (1997). Introduction: Who Needs "Identity"? In S. Hall,\& P. D. Gay(Eds.), Questions of Cultural Identity. London: SagePublications.

Lave, J.,\&Wenger, E. (1991) Situated Learning: Legitimate Peripheral Participation.Cambridge, UK: Cambridge University Press.

Libâneo, J. C. (1995). Education and Educators, for What (11th ed.). São Paulo: Cortez. 
Mello, S. A. (2007). Children and Humanization: Some Thoughts on the Cultural-Historical Perspective. Prospect, 25, 83-104.

Moreira, H. B. (2014). A pedagogia historic-crítica no contexto educacional brasileiro: Reflexões preliminares numa abordagem histórica, teórica e prática. X ANPED SUL, 1-19. http://xanpedsul.faed.udesc.br/arq_pdf/566-0.pdf

Nóvoa, A. (1991). The Past and Present Teachers. In Job Teacher(pp. 13-34). Portugal: Porto Editora LDA.

Perrenoud, P. (2001). Développer her Practice Reflexive dans le métier d'enseignant. Paris: ESF.

Pimenta, S. G. (2012). Teacher Education: Identity and Teaching Knowledge. InPedagogical Knowledge and Teaching Activity (8th ed.). São Paulo: Cortez.

Popkewitz, T. S. (1997).Educational Reform: A Sociological Politics-Power and Knowledge in Education. Porto Alegre: Medical Arts.

Ramalho, B. L., Núñez, I. B., \& Gauthier, C. (2003).Teacher-Professionalize Teaching: Perspectives and Challenges. Porto Alegre: Sulina.

Ribeiro, M. S. S.(2007). The Identity Process. Olinda: Publisher Quick Book.

Robbins, S. P. (1998). Organizational Behavior (8th ed.). Rio de Janeiro: LTC.

Sanches, R. C. F., \& Soares, F. H. M. (2014).Construction of Professional Identity of the Teacher of Law. São Paulo: Legal Letters.

Santos, E. D.,\& Freitas, E. C.(2017). Culture and Identity: Organizational Simulations and Presenting Themselves in Business Speeches. Connection Communication and Culture, 16, 275-295.

Saviani, D. (2003).School and Democracy: Theories of Education, Stick Bend, Eleven Theses on Political Education.Campinas, São Paulo: Authors Associates.

Schön, D. A.(2002). Educating the Reflective Practitioner: A New Design for Teaching and Learning. Porto Alegre: Medical Arts South.

Severino, A. J. (2007).Methodology of Scientific Work. São Paulo: Cortez.

Silva, T. T. (2000).The Social Production of Identity and Difference. InT. T. Smith(Ed.),Identity and Difference; the Perspective of Cultural Studies. Petropolis, RJ: Voices.

Soares, S. R., \& Cunha, M. I. (2010). Teacher Training: University Teaching in Search of Legitimacy. Salvador: Editora da Universidade Federal da Bahia.

Spector, P. E. (2005). Psychology in Organizations. São Paulo: Saraiva.

Tardif, M., Lessard, C., \& Gauthier, C. (2002).Teacher Education and Social Contexts. Portugal: GroundPublisher.

Triviños, A. N. S. (1987).Introduction to Social Science Research: A Qualitative Research in Education. São Paulo: AtlasPublishing Company.

Veiga, I. S. A., \&Viana, C. M. Q. Q. (2010).Teachers for Higher Education: Training Processes. Campinas, São Paulo: Papirus.

Vergara, S. C.(2005). People Management (4th ed.). São Paulo: Atlas.

Vieira, J. N. (2009). The Union and the Teaching Profession Building Space. 2009. $224 \mathrm{f}$. Doctorate Thesis, Natal,Rio Grande do Norte: Federal University of Rio Grande do Norte.

Zabalza, M. A. (2004).University Education: Its Scenery and Its Protagonists. Porto Alegre: Artmed.

Zanelli, J. C., Borges-Andrade, J. E., \& Bastos, A. V. B. (2004). Psychology, Organizations 
and Work in Brazil. Porto Alegre: Artmed.

Zapata, A. (2004). L'épistemologie des pratiques. Pour l'unité du savoir. Paris: L'Harmattan.

Zeichner, K. M. (2003). Forming Reflective Teachers for Education Student-Centered: Possibilities and Contradictions. InR. L. L. Barbosa (Ed.),Educator Training-Challenges and Perspectives. São Paulo: Editora UNESP. 